\section{Amyloids for inflammation}

\author{
By Kai-Jye Lou, Staff Writer
}

Researchers at Stanford University have found that systemic treatment with $\beta$-amyloid peptides can reduce inflammation and reverse paralysis in mouse models of multiple sclerosis. ${ }^{1}$ Cardinal Therapeutics Inc. has licensed the work and now is developing anti-inflammatory amyloids. The company hopes to select a specific indication and name a lead compound by year end.

$\beta$-Amyloid $(A \beta)$ is the plaque-forming protein linked to Alzheimer's disease (AD) pathology. Past studies by academic groups have shown that $\beta$-amyloid is upregulated in multiple sclerosis (MS) lesions. ${ }^{2,3}$ However, the role of $\beta$-amyloid in MS was not well defined, and it was unclear whether it was harmful or protective. A Stanford research group led by Lawrence Steinman published data in 2007 showing that $\beta$-amyloid could be the target of inflammatory processes in MS, thus suggesting it might have a deleterious role. ${ }^{4}$

Steinman is a professor of neurology and neurological sciences, pediatrics and genetics at the Beckman Center for Molecular and Genetic Medicine at the Stanford University School of Medicine.

To further evaluate the significance of $\beta$-amyloid in MS, the Stanford group opted to systemically deliver $\beta$-amyloid peptides to mice with experimental autoimmune encephalitis (EAE), with the expectation that doing so would exacerbate the disease phenotype.

"Based on our previous work, our prediction was that exogenous delivery of $A \beta$ peptides would worsen the disease phenotype of the mouse EAE model," said Steinman.

Much to the group's surprise, $\beta$-amyloid peptides had the opposite effect. Across four different mouse EAE models, intraperitoneal injection of two disease-associated $\beta$-amyloid peptides delayed onset and reduced disease severity compared with vehicle. The peptides also inhibited the production of proinflammatory cytokines in lymphoid tissues.

Moreover, knocking out amyloid precursor protein (APP), the precursor to the two $\beta$-amyloid peptides, exacerbated the EAE disease phenotype in the mouse model.

The results were published in Science Translational Medicine.

"Our work represents a contrarian therapeutic opportunity, and at this stage Cardinal Therapeutics is looking for a partner to help move the science forward," said Steinman, corresponding author on the paper and a cofounder of Cardinal Therapeutics. "I think the biggest concern from a regulatory standpoint is the strong opinions and negative reputation associated with the amyloid class of molecules, but my view is that we need to move the science to where the data are going."
Although $\beta$-amyloid peptides are cytotoxic against immune cell populations that can drive MS, Steinman does not think that is the primary mechanism of action underlying the therapeutic effects in the mouse EAE model. Instead, he suspects the $\beta$-amyloid peptides are acting as binders of proinflammatory cytokines and also forming into protective amyloid fibrils that could inhibit the formation of proinflammatory amyloid fibrils.

Indeed, the cytotoxic effects of the $\beta$-amyloid peptides in vitro did not translate into the mouse EAE model. Moreover, Steinman said unpublished data from mass spectrometry studies suggest the $\beta$-amyloid peptides are binding to proinflammatory mediators in plasma.

Jonathan Rothbard, CSO of Cardinal Therapeutics and a senior research scientist in the Department of Medicine at the Stanford University School of Medicine, said the findings present another example suggesting amyloidogenic compounds could have therapeutic utility in inflammation-related indications.

"In collaboration with Dr. Steinman, we have shown that compounds involved in the formation of amyloid fibrils, such as crystallin $\alpha \mathrm{B}$, can themselves inhibit the formation of other amyloid fibrils," he told SciBX.

Rothbard and Steinman also published data earlier this year showing crystallin $\alpha B$ (CRYAB; HSPB5) can bind to proinflammatory mediators and reduce their concentration in plasma. $^{5}$

\section{Unifying structural features}

Cardinal has a program to develop therapeutic amyloidogenic compounds, and Rothbard
"Right now, we are trying to identify unifying structural features of peptides that could give us insights on how to develop compounds that promote the formation of protective amyloid fibrils."

-Jonathan Rothbard, Cardinal Therapeutics Inc. said the new findings could provide additional insights into the structural features underlying the anti-inflammatory effects of such molecules.

However, he noted that the $\beta$-amyloid peptides used in the paper would not be good therapeutic candidates because they are neurotoxic, have poor solubility and are difficult to synthesize.

"Right now, we are trying to identify unifying structural features of peptides that could give us insights on how to develop compounds that promote the formation of protective amyloid fibrils," Rothbard told SciBX.

He said Cardinal's lead compound would most likely be a peptide or peptidomimetic rather than a small molecule, as the latter class is not known to possess fibril-forming properties.

"The goal at Cardinal is to develop a long-acting amyloid, run the necessary medicinal chemistry studies to optimize its properties and then identify an optimal therapeutic formulation" for the disease we want to treat, said Steinman.

Rothbard said Cardinal's initial disease focus will be in an inflammation-related indication but noted it is unlikely to be MS, as the approval of Gilenya fingolimod and recent regulatory submissions have created a competitive barrier for new entrants. 


\section{ANALYSIS}

Gilenya, an oral once-daily sphingosine 1-phosphate receptor agonist from Novartis AG, was approved in 2010 to treat relapsing forms of MS. Sanofi's Aubagio teriflunomide, a dihydroorotate dehydrogenase (DHODH) inhibitor, also is under FDA and EMA review for relapsing forms of the disease. Earlier this year, Biogen Idec Inc. submitted regulatory applications to the FDA and EMA seeking approval for BG-12, a dimethyl fumarate that activates the nuclear factor (erythroid-derived 2)-like 2 (NFE2L2; NRF2) pathway, in relapsing-remitting MS.

Steinman said that if the group were to settle on MS, the focus would be on populations that still have unmet needs, such as in patients who have primary progressive and secondary progressive disease.

Stanford has issued and pending patents covering amyloids and their therapeutic application to inflammatory disorders. Cardinal has exclusively licensed the IP covering amyloid-based compounds and is seeking a partner. IP covering use of $\beta$-amyloid peptides in MS is available for licensing from the university's Office of Technology Licensing.
Lou, K.-J. SciBX 5(32); doi:10.1038/scibx.2012.831

Published online Aug. 16, 2012

\section{REFERENCES}

1. Grant, J.L. et al. Sci. Transl. Med.; published online Aug. 1, 2012; doi:10.1126/scitransImed.3004145

Contact: Lawrence Steinman, Stanford University, Stanford, Calif. e-mail: steinman@stanford.edu

2. Trapp, B.D. et al. N. Engl. J. Med. 338, 278-285 (1998)

3. Ferguson, B. et al. Brain 120, 393-399 (1997)

4. Ousman, S.S. et al. Nature 448, 474-479 (2007)

5. Rothbard, J.B. et al. J. Biol. Chem. 287, 9708-9721 (2012)

COMPANIES AND INSTITUTIONS MENTIONED

Biogen Idec Inc. (NASDAQ:BIIB), Weston, Mass.

Cardinal Therapeutics Inc., Menlo Park, Calif.

Novartis AG (NYSE:NVS; SIX:NOVN), Basel, Switzerland

Sanofi (Euronext:SAN; NYSE:SNY), Paris, France

Stanford University, Palo Alto, Calif.

Stanford University School of Medicine, Palo Alto, Calif. 